\title{
A FÁBRICA E O MUNDO FABRIL NOS ESTUDOS ACADÊMICOS BRASILEIROS
}

\author{
The Factory and the World Manufacter in the \\ Brazilian Academic Studies
}

João Miguel Teixeira de Godoy*

\begin{abstract}
RESUMO
Levantamento e análise dos estudos clássicos sobre o mundo fabril e seus desdobramentos na produção acadêmica brasileira, enfocando as principais propostas de análises, suas contribuições e seus limites, bem como a abertura para novas possibilidades de estudos.
\end{abstract}

Palavras-chave: Historiografia; sistema fabril; industrialização.

\begin{abstract}
Survey and analysis of the classic studies on the world manufacter and its unfoldings in the Brazilian academic production, focusing the main proposals of analyses, its contributions and its limits, as well as the opening for new possibilities of studies.
\end{abstract}

Key-words: Historiography; system manufacter; industrialization.

As duas últimas décadas do séc. XX foram decisivas para a consolidação da historiografia acadêmica no Brasil. Entre as várias propostas de novos temas que surgiram nesse momento, um conjunto de questões relacionadas ao mundo fabril teve especial atenção. Não que o assunto fosse propriamente novo. Apenas havia surgido de maneira marginal desde os primeiros trabalhos sobre indústria e relações industriais no Brasil. Nesse sentido, as considerações que seguem buscam verificar como alguns estudos

* PUC-Campinas. 
acadêmicos abordaram a questão do sistema de fábrica no Brasil. Minha sugestão é que a incorporação do tema abre possibilidades para uma análise interdisciplinar e mais abrangente de aspectos da história social e econômica brasileira. Nesse sentido, a importância atribuída à questão justificar-se-ia em função de quatro aspectos: 1) por permitir uma redefinição da problemática da industrialização; 2) por possibilitar uma reavaliação da questão da formação da classe operária e da burguesia industrial; 3) por abrir novas perspectivas para a análise dos problemas relacionados à estruturação do poder político e à montagem dos mecanismos de controle social no Brasil a partir do início do séc. XX; e 4) por colocar em questão a historicidade de uma sociedade fundada sobre a convicção do caráter "natural" do mercado e da neutralidade da razão técnica.

Além disso, a tematização da fábrica e do processo de trabalho capitalista deve ser também alinhada a acontecimentos ocorridos na história relativamente recente da sociedade brasileira, mais precisamente no final dos anos 70 e início dos anos 80. De um lado, apresentavam-se os primeiros sinais do esgotamento do modelo de crescimento econômico nacional-desenvolvimentista. Fatores externos atingiram diretamente o modelo econômico, cujo centro nervoso estava constituído pela indústria de bens de consumo duráveis (principalmente automobilística). Do outro, começaram a explodir protestos e greves operárias na região do $\mathrm{ABC}$ paulista, maior parque industrial brasileiro. Nesse movimento, todo um padrão de uso predatório e controle autoritário da força de trabalho começou a ser combatido não apenas fora das fábricas, nos sindicatos e partidos, mas também no interior do espaço fabril, encarado então como um dos locais privilegiados de atuação da classe operária e organização formal do exercício da cidadania operária (HUMPHREY, 1981, 1982; MARONI, 1982).

A escolha das obras a seguir possui caráter preliminar e a análise não as discute por completo. Restringimo-nos à identificação do lugar da fábrica nas interpretações e à demarcação do terreno onde a temática vem surgindo. Ressaltamos que a escolha dos autores obedece a critérios, interesses e limitações pessoais do autor e foram encarados como interpretações representativas de certas linhas teóricas presentes na historiografia. Apresentamos uma breve abordagem de como o problema da fábrica apareceu em alguns textos clássicos para em seguida analisar a produção acadêmica no Brasil. 


\section{Abordagens clássicas.}

A instituição fabril não teve seus elementos tematizados e seus significados discutidos por um único sistema de interpretação ou por um único projeto de reordenamento da sociedade. Na abordagem de Karl Marx, matriz de outros estudos e projetos, a fábrica adquire estatuto de um "sistema" e seu significado revela-se ambivalente: "Por um lado, aparece como progresso histórico e fator necessário de desenvolvimento no processo de formação econômica da sociedade; mas, por outro, ela se revela como meio de exploração civilizada e refinada" (GORZ, 1980, p. 29). Essa ambivalência desdobra-se em outro registro: na relação entre o capital e o trabalho. De um lado, o sistema de fábrica realiza as promessas de subordinação do produtor direto esboçadas na cooperação simples e na manufatura. A fábrica revela-se espaço da alienação, da heteronomia, da disciplina militarizada e do esgotamento físico e intelectual do trabalhador. De outro lado, a dominação fabril aparece como resultado de um conflito fundamental e permanente. Não se constitui num resultado necessário das determinações estruturais, mas numa solução contingente decorrente das práticas sociais ocorridas no chão das fábricas.

Nos debates posteriores, envolvendo os teóricos da social-democracia alemã e do leninismo, a visão da fábrica como espaço do triunfo do capital e da alienação prevaleceu e ofuscou a problemática do conflito. A fábrica não aparece como o lugar do "conflito fundamental", mas como estimuladora da organização e da luta fora dela: nos partidos e sindicatos. Essa visão alinha-se a outra que termina por promover uma verdadeira assepsia política do espaço fabril: a da neutralidade do progresso técnico. O problema não estaria na forma do desenvolvimento das forças produtivas, mas nas relações de produção na qual se situavam. A base material construída pelo capitalismo não seria incompatível com a construção da sociedade socialista, mas condição para isso. Nesses termos, a questão da revolução colocava-se menos no nível das relações de trabalho e mais no nível da organização social e econômica geral. Essa postura permitiu que Lênin, em 1918, recomendasse a adoção sistemática de princípios tayloristas, entendendo conter nele um núcleo racional possível de ser incorporado pela economia socialista (LINHART, 1983). 
Outra abordagem encontra-se nos trabalhos da sociologia industrial norte-americana, nas pesquisas de Elton Mayo em torno das circunstâncias que interferiam no comportamento e produtividade operária no desempenho do trabalho fabril. Tais estudos acabaram chamando a atenção para as práticas, ou "desvios", presentes no comportamento do operário e que se colocavam contrariamente aos interesses da direção das empresas. $\mathrm{Na}$ perspectiva dessa sociologia, mais conhecida como escola das "relações humanas no trabalho", práticas como o absenteísmo, a sabotagem, o impedimento deliberado à normalidade da produção etc. eram abordadas como "problemas", como manifestação do comportamento irracional e inadequado ao trabalho fabril e que precisariam ser contornadas a partir da implementação de técnicas administrativas mais eficazes para as chefias e que incorporassem o trabalhador no "moral" da organização (BENDIX, 1966, p. 322-332). Embora a sociologia das "relações humanas" tratasse das questões fabris a partir de uma perspectiva patronal, revelou o caráter inacabado da submissão do trabalhador e a dependência do capital ao seu engajamento. Nesse sentido, o espaço fabril começava perder a opacidade a que tinha sido reduzido em alguns trabalhos do marxismo clássico.

A partir dessas constatações, novas abordagens procuraram analisar os significados das práticas informais que se desenvolviam no espaço fabril, encarando-as não como "desvios", mas como resistência e como dimensão de um conflito entre capital e trabalho. Outras leituras de Marx contribuíram para essa mudança, que, ao estabelecer um vínculo entre tecnologia e forma histórica de produção econômica, chamava a atenção para os condicionamentos sociais do progresso científico. Para Marx, o processo de inovação tecnológica não estacionava na fábrica. Ele apresentava-se como um ponto de partida de um complexo e dinâmico relacionamento entre evolução técnico-científica, organização do trabalho e disciplinarização dos seus agentes. A mesma lógica implícita na introdução da maquinaria estaria presente no processo de renovação tecnológica a partir da instauração da fábrica. Assim, a fábrica não pode ser vista como espaço de domínio absoluto do capital e isento da ação política. Se a estrutura material sobre a qual assenta-se o poder do capital é uma construção inacabada é porque a insubordinação do trabalho possui o mesmo dinamismo.

Diante dessa realidade, abordagens recentes colocaram suas questões: 1) constitui a fábrica espaço de domínio absoluto do capital, ou espaço 
da formação de uma identidade, amadurecimento político e emancipação da classe operária?; 2) a lógica do progresso tecnológico estaria imune aos condicionamentos sociais e políticos, ou explicita seus conteúdos mais íntimos no terreno conflituoso da dominação social? Em outros termos, seria a técnica expressão material de uma relação de dominação, ou seja, não só na forma como é utilizada, mas no processo de sua elaboração seria a técnica de dominação? Nesse caso, poder-se-ia falar na existência de um padrão de desenvolvimento tecnológico adequado às relações sociais de produção capitalista? Poder-se-ia falar no fim da contradição entre forças produtivas e relações de produção e a abolição das influências revolucionárias da primeira sobre a segunda? As tentativas de responder a essas questões constituem o tema dos vários escritos (CASTORIADIS, 1985; GORZ, 1980; MARCUSE, 1973; HABERMAS, 1980). Apesar de suas diferenças, um princípio básico permanece: a investigação acerca do significado da fábrica não pode ser feita isoladamente da investigação das relações sociais engendradas antes dela e aprofundada a partir dela.

Essas tendências também se manifestaram em movimentos como o obreirismo, influenciados por ideias de autores como Gramsci, e procuraram repensar a luta de classes a partir das fábricas. Fizeram a crítica à burocratização dos sindicatos e sua incapacidade de absorver a vida que brotava nas fábricas e aos partidos comunistas que adotavam a esfera estatal como campo privilegiado de atuação política.

\section{A questão da fábrica no tema da industrialização}

A identificação entre a fábrica, o espírito empreendedor do grupo empresarial e o desenvolvimento industrial assumiu um caráter dominante não apenas na literatura especializada sobre o assunto, mas também nas representações construídas pela sociedade sobre seu próprio progresso. A proliferação e a expansão das grandes fábricas, a generalização dos processos mecanizados, a energia elétrica, as massas operárias e uma burguesia triunfante apresentam-se como realidade concreta, visível, daquilo que geralmente se entende por industrialização, por modernização e por progresso social. 
Encarada dessa maneira, porém, a modernização e seus elementos constituintes perdem densidade social e histórica e aparecem como expressão de um projeto humano - purificado dos interesses econômicos e políticos exclusivistas - cujo objetivo central seria a construção da nação como comunidade envolvente e harmônica. Nesse contexto, o aumento quantitativo das unidades fabris e o aumento ilimitado da capacidade de produzir bens, permitido pela máquina e pela ciência aplicada, constituiriam a dimensão econômica de um movimento mais abrangente rumo ao progresso e à modernidade.

Alguns trabalhos de história econômica brasileira caminharam nesse sentido, reforçando as posições defendidas pelo desenvolvimentismo, em cuja ótica industrialização e sistema fabril significavam desenvolvimento econômico em geral e progresso científico, mascarando sua essência de etapa de desenvolvimento de um sistema econômico particular - o capitalismo -, correspondendo a escolhas e projetos de setores específicos da sociedade (no caso a burguesia) (SILVA, 1996; MELLO, 2009). Essas pesquisas e as prescrições da CEPAL para a economia latino-americana nos anos 50 expressam essa visão. No Brasil, a visão cepalina aparece claramente nos trabalhos de Celso Furtado. No seu Formação econômica do Brasil, formula os fundamentos de um projeto de industrialização tendo por base o modelo inglês, adaptado às necessidades nacionais, mas com particularidades, acelerando-se o processo e eliminando-se etapas. Nas suas análises, o autor incorpora a ideia de fábrica; sua implantação, entretanto, aparece essencialmente como resultante da propagação do progresso técnico dos países centrais para os países periféricos, ou seja, da "assimilação de processos tecnológicos mais complexos" (FURTADO, 2007, p. 198) via intercâmbio externo e a consequente mecanização dos processos manufatureiros. Essa mudança é vista como processo linear, progressivo, acumulativo, politicamente neutro e determinado por acontecimentos de natureza puramente tecnológica, cujo resultado final seria a conclusão de uma longa trajetória com o objetivo maior de formação de uma economia nacional e autônoma. As implicações do sistema de fábrica, em termos de dominação política e controle social do capital sobre o trabalho, ficam ausentes de sua análise (MANTOUX, 1990). As contradições, conflitos e tensões políticas e sociais que tal processo de transição desencadeia ficam encobertas por uma abordagem estritamente econômica da questão. 
O centro das críticas às teses cepalinas foi, justamente, a ausência de questionamentos sobre a natureza do projeto de desenvolvimento proposto. Comentando alguns aspectos das teses de Furtado, Florestan Fernandes, em 1959, apontava, em primeiro lugar, o caráter pragmático de suas conclusões no que dizia respeito aos problemas práticos colocados por esse desenvolvimento. Para Florestan, esses problemas eram

propostos e examinados em termos da situação da economia brasileira e de suas tendências de transformação em um sistema capitalista de escala nacional. Aí está, possivelmente, a única fonte considerável de limitação de suas elaborações teóricas, confinadas à pressuposição de que a dinâmica ideal do sistema econômico brasileiro é definida pelo conjunto de condições que tendem a assegurar sua integração como economia capitalista.

Chamava atenção, ainda, para o desinteresse de Furtado com relação a aspectos relacionados à "operação real dos mecanismos econômicos na sociedade brasileira”, ou seja, as diferenças geográficas, composição da população, mecanismos psicossociais e organização das relações sociais, elementos que interferiam nos processos de desenvolvimento e que não poderiam ser ignorados sem comprometer os resultados alcançados (FERNANDES, 1959).

Nas páginas da Revista Brasiliense, durante os anos 50 e início dos anos 60, surgiram outras teses que procuravam estabelecer contraponto com o nacionalismo cepalino. Em artigo intitulado "Nacionalismo e Desenvolvimento", Caio Prado Jr. teceu críticas à concepção econômica defensora da ideia de que a conquista, pelo Brasil, de um estatuto nacional e de uma condição de autonomia no conjunto da economia internacional seria meramente consequência do seu desenvolvimento econômico, via modernização das forças produtivas. Contrapôs-se a essa ideia invertendo a relação causal entre os dois conceitos, defendendo que uma política nacionalista seria a condição precípua de um real desenvolvimento econômico (PRADO JR., 1959)

Dissecando a concepção de desenvolvimento e subdesenvolvimento, que no final dos anos 50 estava implícita nas diretrizes e normas da política econômica implementada pelo Estado, apontava sua fundamentação na crença de um modelo e de um padrão básico de organização econômica 
e na existência de uma trajetória de progresso que deveria ser única, unilinear, homogênea e previamente estabelecida. Nessa trajetória estariam distribuídas as diferentes economias nacionais, a partir do critério de maior ou menor proximidade com o modelo padrão, posição dada pela medição quantitativa do nível de seu desenvolvimento, ou seja, a renda nacional per capita de cada país.

Caio Prado Jr. mostrava como a teoria do desenvolvimento supervalorizava as diferenças quantitativas em prejuízo das diferenças qualitativas, estas sim fundamentais para a elaboração de uma teoria e de uma política promotoras do real desenvolvimento nacional. De acordo com sua visão, o "capitalismo [...], constitui um sistema de conjunto em que cada um deles [os países], ou grupos mais ou menos homogêneos, ocupam situações qualitativamente diversas que não se reduzem a um simples escalonamento de progresso econômico ou de estágio de desenvolvimento capitalista". Dentro desse conjunto articulado de diferentes realidades econômicas e sociais o "subdesenvolvimento" denominaria, sobretudo, uma situação periférica e complementar no quadro internacional. Caracterizaria, segundo Caio Prado Jr., uma situação "subordinada e dependente", onde as economias periféricas se especializariam no fornecimento de matérias-primas para os países centrais do sistema (PRADO JR., 1959, p. 11).

Diante dessa avaliação, sua sugestão era de que a elaboração das diretrizes e normas para uma nova política econômica deveria estar subordinada primeiramente ao objetivo de se superar a posição periférica e a condição complementar da nossa economia. Esse novo projeto implicaria em mudança estrutural, organizando a economia brasileira em "bases propriamente nacionais", de acordo com as "necessidades da massa da população brasileira". Deveria, portanto, romper com os fundamentos daquilo que em outro trabalho ele denominara "economia colonial” (PRADO JR., 1981). A concretização desse objetivo não estaria meramente na industrialização, entendida como progresso técnico e econômico em geral, mas num "tipo de industrialização", diferente da simples substituição das importações, através de instalação no país de filiais das grandes organizações industriais internacionais. Esse modelo, apesar dos estímulos ao desenvolvimento que poderia inicialmente trazer, atrelava a continuidade do processo à inserção da economia nacional na divisão internacional do trabalho como fornecedora de matérias-primas: modelo, portanto, que não rompia com a dependência 
externa. Concluía afirmando que o desenvolvimento industrial deveria se dar de maneira integrada na economia nacional, "isto é, que seja, como iniciativa, essencialmente brasileira; e que em consequência seja estimulada e condicionada não pelo objetivo de lucro de empreendimentos estrangeiros e por interesses estranhos à coletividade brasileira, e sim pelos próprios estímulos e impulsos internos da vida econômica do país" (PRADO JR., 1959, p. 15).

Outro aspecto importante diferia a posição de Caio Prado Jr. das conclusões e projetos da Economia Política dos cepalinos. Em artigo publicado na mesma Revista Brasiliense, em 1961, analisou o desenvolvimento econômico a partir de um processo interno de acumulação, perspectiva reveladora de oposições e conflitos, decorrentes da relação salário e lucro. Enquanto as teses cepalinas enfocavam apenas os impactos internos que a importação de tecnologias provocava nas funções macroeconômicas de produção, Caio Prado Jr. considerava a questão do ângulo do proletariado e suas consequências em termos de aprofundamento das relações sociais de produção capitalista (PRADO JR., 1961).

Muitas das críticas e observações desencadeadas pelos trabalhos de Furtado e à vigência das teses da CEPAL no Brasil nos anos 50 e início dos anos 60 foram posteriormente desenvolvidas e aprofundadas por autores como Fernando H. Cardoso e Enzo Faletto, na elaboração da chamada "teoria da dependência", e retomadas, posteriormente, nas análises sobre o caráter da industrialização brasileira de João Manuel Cardoso de Mello e Sérgio Silva, entre outros.

Antes de considerarmos as obras desses autores, é importante mencionar a contribuição do trabalho de W. Dean para o debate a respeito das origens e da natureza do processo de desenvolvimento industrial brasileiro. Seu livro A industrialização de São Paulo (DEAN, 2001) lançou as bases da teoria da "Industrialização induzida pelas exportações". O ponto controverso entre as teses de Dean e de Furtado reside no caráter da relação entre o setor exportador (a lavoura cafeeira principalmente) e o setor voltado para o mercado interno (indústria), ou seja, se esta relação era de incompatibilidade ou de complementaridade. Segundo Dean, ao contrário das afirmações da "teoria dos choques externos", defendida por Furtado, a relação era diretamente proporcional entre a expansão das vendas de café no mercado internacional e o crescimento industrial interno. $\mathrm{O}$ acúmulo de divisas permitiria a im- 
portação de equipamentos e insumos para garantir a ampliação do parque industrial. Detalhando as conexões entre o café e a indústria, apontou como a mais importante, mais até que a capacidade de garantir as importações de bens de produção, o surgimento de condições para a formação de uma elite econômica, cultural e tecnicamente instrumentalizada, capaz de garantir o sucesso de empreendimentos industriais. Nesse sentido, afirma: "Por mais adequadas que se apresentem as circunstâncias para a industrialização, a decisão de destinar recursos a esse propósito não será tomada enquanto as percepções e interesses da elite não estiverem favoravelmente empenhados" (DEAN, 2001, p. 22). Dean atribui, assim, ao fator cultural função fundamental na explicação das transformações históricas: "Pode-se dizer que suas decisões [dos industriais] causaram a industrialização no sentido mais direto da palavra "causar"” (DEAN, 2001, p. 20).

Coerente com essa perspectiva, a fábrica aparece, na análise de Dean, como a pura expressão da vontade e da ação empresarial. Esse ponto de vista convive, em seu trabalho, com o pressuposto de que o crescimento industrial e a maior racionalização da produção fabril dependem de condicionantes tecnologicamente orientados e condições de mercado favoráveis. A partir dessa perspectiva, vários aspectos das fábricas paulistas nos anos 20 são analisados: as duras condições de trabalho, os baixos salários, o emprego sistemático da mão de obra infantil e feminina, as longas e estafantes jornadas de trabalho, a ausência de medidas de proteção ao trabalhador dentro das fábricas, os ambientes fabris inóspitos, a baixa qualidade da matéria-prima, a não aplicação das poucas normas de proteção ao trabalho que começavam a surgir nos anos 20, as máquinas ultrapassadas e mal distribuídas no espaço fabril, os frequentes acidentes de trabalho etc.

Sobre essa realidade e determinando suas características centrais, Dean fala da construção de posturas empresariais e de padrões de uso e controle da força de trabalho. A identificação entre empresa e propriedade familiar teria dado origem a um modelo autoritário de relação entre os industriais e seus operários, fundamentando ao mesmo tempo uma concepção corporativista da ordem social.

Essa concepção da fábrica e da empresa como um negócio estritamente privado e a ação empresarial decorrente dessa representação é um aspecto importante do estudo de Dean. As estratégias de controle do espaço fabril montadas nas primeiras décadas do séc. XX pelo Centro dos 
Industriais de Fiação e Tecelagem de São Paulo (CIFTSP), cujo objetivo era contrapor-se ao recrudescimento do movimento operário através do expurgo realizado nas fábricas, constituem fatos reveladores da percepção patronal a respeito da fábrica e do papel que deveriam cumprir nela. Essas características, entretanto, não são analisadas como elementos inerentes ao sistema de fábrica que historicamente vão se articulando e aprimorando-se em virtude das práticas operárias de resistência. Entendemos que essas práticas desempenham papel fundamental na dinâmica do crescimento industrial e do aperfeiçoamento tecnológico. Para Dean, a ideologia autoritária e patrimonialista que orienta a ação empresarial é característica universal dos momentos iniciais de implantação do sistema capitalista e tende a ser superada na medida em que o sistema se consolida.

Os estudos de João Manuel Cardoso de Mello, Sérgio Silva e Wilson Cano discutem principalmente o impasse a respeito da origem e da natureza do processo de industrialização, criado pelo debate entre as teorias explicativas anteriores, e nos interessam na medida em que analisam o surgimento das grandes fábricas mecanizadas e a não existência, no nosso processo de industrialização, das etapas anteriores caracterizadas pelo artesanato e pela manufatura, tal como teria ocorrido no desenvolvimento do capitalismo nos países avançados.

Divergindo de Celso Furtado, esses autores não encaram a instalação das fábricas como resultante de um processo tecnologicamente orientado e restrito ao campo do desenvolvimento das forças produtivas. As fábricas não surgem unicamente como expressão dos interesses econômicos imediatos de determinados grupos da elite paulista dos anos $1910 \mathrm{e}$ 1920, como parece sugerir Dean. Para Sérgio Silva, por exemplo, a fábrica representa uma etapa conclusiva de uma revolução no processo de trabalho, determinada por relações sociais de produção mais amplas, que são as relações capitalistas. A fábrica representaria a materialização do domínio que o capital exerce sobre o trabalho, não mais formalmente, como ocorria na manufatura, mas como realidade técnica, transformando o trabalhador num mero complemento da máquina (SILVA, 1996, p. 14-15).

Quais foram as condições históricas que determinaram o nascimento da fábrica no Brasil? Para esses autores, o desenvolvimento da economia brasileira, a partir das últimas décadas do séc. XIX, representava o aprofundamento de relações capitalistas. A instalação de grandes unidades 
produtivas e a organização do processo de trabalho nos moldes fabris atendia às necessidades colocadas para o aprofundamento dessas novas relações. $\mathrm{O}$ modo como esse processo ocorreu concretamente e suas consequências na definição das características do desenvolvimento capitalista brasileiro podem ser compreendidos a partir das interpretações que seguem.

Segundo Wilson Cano, a dimensão e a estrutura setorial da indústria brasileira nas suas origens correspondem aos interesses da economia cafeeira. A instalação da grande indústria mecanizada não representou um confronto com a economia cafeeira, mas, ao contrário, um setor de investimentos desse mesmo capital. Reproduziu, portanto, a mesma estrutura de concentração da propriedade e da renda da economia cafeeira. Reforçando essa tendência, havia ainda a questão da "rigidez tecnológica" dos equipamentos industriais oferecidos no mercado internacional, condicionando a formação de economias de grande escala. Os ramos predominantes foram aqueles adequados ao processo de racionalização por que vinha passando a produção de café no final do séc. XIX, ou seja, indústria de máquinas e implementos para a agricultura e beneficiamento, indústria de sacaria de juta para embalagem e indústria de bens de consumo corrente. O objetivo central da instalação das grandes fábricas nos setores apontados foi a diminuição dos custos de reprodução da força de trabalho, aumento de produtividade, aceleração da circulação dos produtos e, consequentemente, redução dos preços das matérias-primas necessárias ao desenvolvimento dos países industrializados, de acordo com a lógica implantada pela divisão internacional do trabalho.

Sérgio Silva parte dessa última consideração para explicar por que a industrialização brasileira ocorreu queimando etapas. Isto é, por que ocorreu a partir da instalação da fábrica mecanizada, sem ter passado anteriormente pelo artesanato e pela manufatura. Para ele, a análise desse processo deve levar em conta as especificidades do desenvolvimento do capitalismo no Brasil, onde o capital cafeeiro teve uma posição dominante no interior de uma economia subordinada à economia mundial. A chave, portanto, para a compreensão das formas de reprodução do capital industrial estaria na divisão internacional do trabalho. A especialização setorial na produção de bens de consumo e os limites impostos ao desenvolvimento da indústria de base canalizavam a demanda por máquinas e equipamentos industriais para os países desenvolvidos, principalmente a Grã-Bretanha, preservando 
os mecanismos de subordinação. A possibilidade de a indústria brasileira importar equipamentos modernos e adotar técnicas avançadas, garantindo uma rentabilidade elevada, teria condicionado os investimentos em grandes escalas, além de um rápido e seguro processo de acumulação.

A questão do sistema de fábrica aparece nesses estudos, notadamente no de Sérgio Silva, não como enfoque específico, mas como dimensão da consolidação do capitalismo no Brasil na sua forma peculiar e subordinada. Elabora-se uma interpretação da origem, da natureza e dos limites da grande indústria, enfatizando as contradições da economia cafeeira na sua relação com a economia mundial. A grande fábrica mecanizada não surge de maneira ameaçadora para a natureza dependente do capitalismo brasileiro. A fábrica repõe e incorpora a lógica da dependência.

Mas esses trabalhos, que viram na indústria e no sistema de fábrica a dimensão técnica do desenvolvimento das relações de produção capitalista no Brasil, não se detiveram numa análise mais profunda do mundo fabril (SILVA, 1996; CANO, 1986; MELLO, 2009). Este permaneceu obscurecido por uma abordagem homogeneizadora e generalizante do processo de industrialização. Por um lado, a industrialização, no sentido estrito da palavra, realizava-se a partir da consolidação de uma estrutura fabril, em cuja evolução clássica a fábrica apareceria como o resultado de um processo de divisão do trabalho, mecanização da produção e subordinação real do produtor direto, que começaria no artesanato, passaria pela manufatura e finalizaria na fábrica. Por outro, nos países "novos", de industrialização recente, como o Brasil, esses estágios teriam sido saltados e a fábrica acabou surgindo como um transplante externo, devido à facilidade de acesso aos maquinários, tecnologias e mão de obra especializada, presentes no mercado internacional, e à capacidade de importação proporcionada pelos excedentes de capital gerados na economia cafeeira ${ }^{1}$.

O conceito de sistema de fábrica abre novas perspectivas de abordagens dessas questões, pois valoriza, principalmente, a dinâmica instaurada pelo conflito entre capital e trabalho para analisar o processo de inovação tecnológica e a adoção de novas formas de organização fabril e gestão da força de trabalho. Embora Sérgio Silva considere o desenvolvimento

1 Essas colocações são comuns a diferentes trabalhos, de diferentes linhas, sobre a economia e a industrialização brasileira. Está presente nos trabalhos de Celso Furtado e até nas interpretações mais recentes de Sérgio Silva e Wilson Cano, entre outros. 
industrial como "transformação do processo de trabalho pelas relações de produção capitalistas" e como "reforço da dominação do capital sobre o trabalho" (SILVA, 1996, p. 15), dá pouca atenção ao processo de dominação enquanto tal, encarado como dado absoluto e estático. A fábrica seria o espaço revelador da consolidação desse poder.

\section{O tema da fábrica e as classes sociais}

Vários estudos têm refletido sobre o lugar ocupado pela classe operária e os significados da sua presença na consolidação da sociedade industrial e do capitalismo no Brasil ${ }^{2}$. No conjunto, organizam-se em ciclos teórico-interpretativos. Teríamos um ciclo autoritário, fundado numa concepção de terror em relação aos trabalhadores e numa prática de controle coercitivo; um ciclo paternalista, baseado no exercício da tutela e na manutenção da heteronomia da classe, onde o trabalhador transfigura-se de inimigo potencial no colaborador da construção do projeto nacional; um ciclo revolucionário, fundado na convicção de que a classe operária encarna as possibilidades de mudanças inscritas no processo histórico, atualizadas ora por uma tomada de consciência e mudança dos padrões morais de convivência social, desembocando numa ação direta contra os pilares da ordem burguesa, ora representada por uma vanguarda que atinge o limite da consciência do destino histórico da classe; e um ciclo acadêmico, quando a classe operária tornou-se objeto de estudos mais sistemáticos, apreendida agora por procedimentos "científicos", pretensamente expurgados dos elementos ideológicos que seriam comuns nas abordagens anteriores ${ }^{3}$.

2 As contribuições e os limites desses trabalhos, assim como os dados bibliográficos, podem ser verificados a partir da leitura de vários balanços bibliográficos (RODRIGUES; MUNHOZ, 1974; PINHEIRO, 1977; VIANNA, 1978, 1984; MUNAKATA, 1980; PAOLI; SADER; TELLES, 1983; FAUSTO, 1988).

3 Como chama a atenção Hobsbawm, se muito da vida palpitante da classe operária, de suas múltiplas potencialidades e significados perderam-se no campo "purificado" da abordagem científica, o caráter acadêmico em ascensão dos estudos operários, além das transformações presentes na conjuntura política, acabariam por corrigir algumas tendências implícitas típicas das produções não acadêmicas, assim como a tendência forte de se reduzir a "classe operária" ao "movimento operário", a tendência de se isolar o movimento operário do contexto social mais amplo e a tendência de se criar modelos e versões oficiais sobre os significados da sua atuação (HOBSBBAWM, 1987, p. 17-34). 
Nos trabalhos acadêmicos, podemos identificar abordagens diversas. Numa primeira perspectiva, a fábrica aparece como reflexo das transformações estruturais que marcaram a sociedade brasileira até os anos 1950. Esse momento representaria a transição da "sociedade tradicional" para a "sociedade de mercado". As especificidades da organização fabril e seus significados sociais não constituiriam o foco central da análise, mas aspecto indireto e expressão passiva das mudanças que ocorrem aquém ou além da fábrica, mas nunca a partir dela e com ela.

Os estudos representativos dessa perspectiva foram os de Juarez Brandão Lopes, reunidos sob o título Sociedade industrial no Brasil (LOPES, 1964). Como o próprio título sugere, a questão central refere-se à lógica que rege o comportamento do trabalhador no sistema industrial. Mas não qualquer trabalhador e nem qualquer sistema industrial ${ }^{4}$.

O padrão de conduta dominante entre os trabalhadores dependeria da natureza da estrutura institucional, do sistema de ideias e valores sociais que a complementam. Essa postura sugeria uma relação direta entre determinações estruturais e comportamento, onde este não passaria de um reflexo daquelas. Pretendia verificar, portanto, como ocorreu esse processo de determinação.

A imagem de classe operária que emergiu dessa análise correspondeu àquilo que Paoli, Sader e Telles denominaram o "paradigma da classe subordinada"s: uma classe não ajustada ao mundo urbano-industrial, sem identificação com a condição operária, sem padrão de ação coletiva e com visão puramente instrumental do trabalho industrial, do sindicato e da legislação trabalhista.

Nessas análises, a fábrica aparece como local onde a classe operária pode ser encontrada, mas não onde a classe se realizaria enquanto tal. Em termos técnicos e organizacionais, o espaço fabril apareceu como objetivação de uma estrutura industrial incipiente. A fábrica estudada trazia

4 Segundo o próprio Juarez: "Fundamentalmente, a motivação do trabalho é a mesma em todas as sociedades: a satisfação de necessidades e desejos, a autoestima, o reconhecimento social etc. As formas concretas, porém, em que esses motivos básicos se expressam, dependem da sociedade e, por conseguinte, variam" (p. 24).

5 Ou seja, uma classe cujas características fundamentais não são definidas por sua realização histórica concreta, por suas práticas e experiências, mas por condições externas, estruturais, sobre cuja dinâmica não interfere. Ver Maria Célia Paoli, Eder Sader e Vera da Silva Telles: Pensando a classe operária: os trabalhadores sujeitos ao imaginário acadêmico (1983). 
elementos de modernização técnica, mas era nos aspectos organizacionais e administrativo, cujas formas e efeitos dependiam da natureza da estrutura da autoridade, que as características "tradicionais" e os desajustamentos em relação à lógica que comanda o padrão de decisão racional apareciam de maneira explícita.

Na medida em que o ponto de partida do processo de interpretação era o estabelecimento do tipo ideal como referência principal, junto à preocupação de identificar as variáveis estruturais que interferiam no grau de aproximação ou distanciamento da realidade histórica em relação a esses tipos, a relação entre classe operária e a fábrica tornou-se meramente formal e mecânica. Em primeiro lugar, porque a classe não tinha nas experiências vividas na fábrica - e na interpretação que construía sobre essas experiências - a base de construção de sua identidade e formas de conduta, e sim nos vínculos que mantinha com os valores e ideias da sociedade de origem. A predominância dos valores tradicionais sobre as experiências concretas de dominação e exploração esvaziava a fábrica das potencialidades que possuía enquanto espaço possível de construção de uma identidade coletiva a partir de uma comunidade de interesses e vivências. Em segundo lugar, porque a fábrica apareceu como reflexo dos movimentos estruturais em determinadas etapas do desenvolvimento industrial, perdendo a dimensão central do sistema de fábrica relacionado à problemática da dominação e do conflito social. O sistema de fábrica, segundo Karl Marx, não era apenas um modo inédito de organizar o trabalho, mas mecanismo voltado para garantir o sucesso do processo de valorização do capital. A fábrica concretizava estratégias cujo objetivo era garantir que a força de trabalho se tornasse trabalho de fato, realizado e objetivado em mercadorias. Essa exigência implicava no uso de recursos coercitivos e consensuais garantidores da mobilização dos produtores diretos e que impregnava não apenas os aspectos organizacionais e administrativos de uma empresa, mas também seus aspectos técnicos. Nessa perspectiva, a fábrica não poderia ser considerada apenas a face mais visível da estrutura econômica de países que se encontravam numa fase intermediária entre o tradicional e moderno, mas produto de uma correlação de forças inscritas num quadro mais geral, determinado por relações sociais de produção mais abrangentes.

A ruptura com a concepção de fábrica enquanto instituição restrita ao mundo da produção ocorreu, de um lado, a partir das mudanças na 
conjuntura política do movimento operário, onde espaços até então não consagrados de atuação política adquiriram nova importância e, de outro, a partir de uma renovação teórica ${ }^{6}$.

As novas abordagens fundamentam-se num conjunto de premissas: 1) o ponto de partida implica abandonar uma postura onde o espaço fabril é considerado espaço do domínio exclusivo da racionalidade técnica e apolítica, ressaltando, em contrapartida, os conteúdos de dominação social embutidos nessa mesma racionalidade; 2) em segundo lugar, chamam a atenção para os significados dos conflitos informais que se desenvolvem no chão da fábrica, pois eles representam mais do que simples "desajustamentos" ao sistema industrial de contingentes recém-urbanizados. Ao impor sua lógica, o capital não prescinde de uma adesão "voluntária" dos produtores, ao mesmo tempo em que não os integram totalmente sem colocar em risco essa mesma lógica. É nesse espaço fugidio que se instauram o conflito e a luta incessante. Luta dissimulada muitas vezes, mas que pode concretizar-se em reivindicações econômicas ou projetos revolucionários (CASTORIADIS, 1975). Nesse sentido, a fábrica apresenta-se não mais como espaço exclusivo da dominação, mas igualmente espaço de resistência e luta, espaço de construção de uma identidade política operária; 3 ) em terceiro lugar, a fábrica mantém vínculos com a montagem de um sistema de dominação política, ou seja, o equilíbrio entre os mecanismos de controle operário centrado no par coerção-consenso acabam por determinar a predominância de um ou outro nível do quadro institucional (VIANNA, 1988).

Alinhado com essas perspectivas, um grupo de estudos tem procurado enfocar o desenvolvimento industrial brasileiro a partir da atuação empresarial no nível das fábricas? ${ }^{7}$.

A preocupação é resgatar a importância e o desempenho ativo da burguesia industrial no processo de construção do capitalismo brasileiro, não só no nível do aparelho de Estado e na reordenação do mercado de trabalho, mas também na atuação empresarial propriamente dita: na organização do processo produtivo e na gestão e controle da força de trabalho no interior dos estabelecimentos industriais ${ }^{8}$.

1987.

6 Ver Castoriadis, 1985; Gorz, 1968,_1980, 1982; Marglin, 1980; Dickson, 1978; Foucault,

7 Ver Turazzi, 1989; Ribeiro, 1988; Matos, 1991; Machado Filho, 1984.

8 Segundo Eli Diniz, "A despeito da não hegemonia, aprofundando a análise de sua atuação política, é possível detectar a capacidade revelada pelo grupo no sentido de sustentar um projeto de 
Além de unidade temática, os trabalhos mencionados possuem unidade temporal e geográfica: o período de análise restringe-se à primeira fase do processo de industrialização centrado nas cidades de São Paulo e Rio de Janeiro. Nesse contexto, procuram identificar os traços distintivos e a construção de um padrão de organização fabril e de uso e controle da força de trabalho. Procuram enfatizar, sobretudo, o caráter autoritário e, ao mesmo tempo, despótico e paternal, marcante nas relações entre patrões e trabalhadores.

O estudo de Maria Inez Turazzi propõe "desnudar" as estratégias e os argumentos empregados pela indústria carioca, no sentido de legitimar uma estrutura hierárquica na organização do processo de trabalho e no exercício da autoridade no interior das fábricas, onde a ocupação pelos patrões dos postos de comando e coordenação do trabalho coletivo obedeceria a imperativos antes de tudo técnicos e racionais.

Nesse sentido, as matrizes ideológicas que forneceram os argumentos e conteúdos das estratégias legitimadoras da autoridade patronal teriam se inspirado no positivismo, com seus ideais de "progresso pelo trabalho", "ordem pela disciplina" e "virtude pela pobreza"; no liberalismo e seus princípios de função social da indústria e não interferência do Estado no mercado de trabalho; e, finalmente, a economia política clássica e sua defesa da divisão social do trabalho como condição "progresso" e defesa da propriedade privada (TURAZZI, 1989)

Mas, as práticas concretas e o desempenho cotidiano do empresariado industrial no sentido de assegurar a efetividade das suas ordens e a eficácia do trabalho nas fábricas ficam demonstrados de maneira mais completa no trabalho de Maria Rosa Ribeiro, que estuda a industrialização paulista sob o ponto de vista da organização do processo de trabalho e das relações sociais instituídas entre o capital e o trabalho nas fábricas. Preocupa-se em recuperar as condições de trabalho na indústria têxtil paulista até os anos 1920. Nesse sentido, discute inicialmente as características estruturais da indústria têxtil (nível técnico avançado, concentração e centralização do capital etc.) e suas condições históricas de expansão (ausência de limites

dominação capitalista, cujos rumos contribuiria para definir. [...] Nesse sentido, as limitações ideológicas ressaltadas, longe de apontar para a passividade do grupo, caracterizam um estilo de atuação voltada, se não para a captura do Estado, pelo menos para a redefinição dos objetivos não negociáveis do sistema capitalista" (1978, p. 295). 
legais na exploração da força de trabalho, protecionismo, mercado de trabalho abundante e mercado de consumo em expansão). Em seguida, analisa a atuação empresarial nesse processo, principalmente em relação ao controle e à disciplinarização do produtor direto no interior das fábricas.

A questão da organização do processo de trabalho aparece como a forma mais eficaz de se discutir e recuperar as condições de trabalho na indústria têxtil, caracterizada pelo uso intensivo e extensivo de máquinas, por um ambiente de trabalho em condições precárias do ponto de vista da higiene, da disposição das máquinas etc.; pela desqualificação do trabalho e pelo uso generalizado de mulheres e crianças; pela rígida disciplina; pela fixação das jornadas determinadas pelos interesses do processo de acumulação; e pelas baixas remunerações, definidas por critérios desconhecidos pelos trabalhadores.

Discutindo essa mesma problemática, só que para a indústria de sacaria, temos o trabalho de Maria Izilda de Matos. Sua análise se detém sobre dois aspectos centrais: suas características estruturais, o que nos remete aos vínculos entre setor industrial e economia agroexportadora, e as características presentes na organização do processo de trabalho fabril.

A particularidade desse estudo está na maior ênfase dada ao papel da mulher trabalhadora, em termos de atuação no processo produtivo e nas práticas de resistência à lógica instituída pelo capital nos locais de trabalho. Em segundo lugar, Maria Izilda discute com detalhes as várias fases e a dinâmica de construção de uma identidade social burguesa entre os empresários do setor de sacaria, principalmente no que diz respeito à elaboração de "matrizes discursivas" orientadoras da ação empresarial dentro e fora da fábrica.

O trabalho de Oswaldo Machado Filho, além de esmiuçar o processo de construção de um padrão despótico do exercício da autoridade nas indústrias têxteis paulistas, assim como suas consequências na definição das condições de trabalho aí reinantes, discute outra problemática que nos remete a outro conjunto de estudos onde a questão da fábrica aparece de forma diferenciada dessa que estamos discutindo até agora. Refiro-me aos trabalhos de Edgar de Decca $(1986,1987)$ e Luiz Werneck Vianna (1983).

Nesses estudos, os enfoques privilegiam a relação entre fábrica e estruturação do poder no nível da sociedade. Em Machado e E. de Decca, o ponto de partida está no debate sobre as possibilidades de transformação 
social dentro dos marcos institucionais da sociedade industrial moderna. A questão central seria a seguinte: o sistema de fábrica, mecanismo que consolida o domínio burguês na sociedade do trabalho, seria capaz de resolver os problemas que envolvem essa sociedade e garantir a passagem para uma nova ordem assentada na abundância, na liberdade e no fim do trabalho alienado, ou, pelo contrário, essas possibilidades não passariam de uma ilusão necessária, criada pelo próprio sistema em busca de legitimação? Em outros termos: a ideia de progresso e as promessas de um novo mundo que podem se efetivar, ou essas convicções apenas ocultam uma ligação irremediável entre progresso industrial e aprofundamento das formas de dominação e exploração social?

Com o objetivo de aprofundar a discussão, os autores analisam o processo de desenvolvimento brasileiro, privilegiando, no caso de E. de Decca, a instalação do engenho de açúcar no período colonial (DECCA, 1987, p. 10) e o momento de surgimento de uma ideologia industrialista no final dos anos 1920. Machado privilegia o setor têxtil entre o final do séc. XIX até os anos 1930.

A abordagem segue duas estratégias: primeiro, a crítica à historiografia sobre o tema da industrialização, ressaltando sua identificação com uma memória instituída pelos grupos vencedores nesse processo. Em segundo, a pesquisa de fontes primárias, procurando identificar as condições reais em que tal projeto foi formulado, refazendo a perspectiva analítica sobre a industrialização, colocando-a como síntese de um processo de luta, com a fábrica no papel central, e onde a ideia de "mercado" aparece envolvida nessa luta entre forcas sociais divergentes.

Mas o que é o sistema de fábrica? É mais do que mecanismo de exploração e reprodução das relações capitalistas. Melhor dizendo, ele é exatamente isso, mas num sentido mais amplo, num sentido político e ideológico. Ele garante a exploração e controle do trabalhador, na medida em que cria a própria figura do trabalhador disciplinado. No processo de exploração-dominação, a fábrica dá origem a uma nova racionalidade, onde sua existência apareceria como dado natural, objetivo, imposto por forças neutras da ciência, impossíveis, portanto, de serem contestadas. Daí a necessidade de se refazer mais uma vez as condições históricas de sua implantação como estratégia para reviver na memória sua verdadeira face de dominação. Será nesse momento que as lutas e resistências operárias 
podem ser analisadas quanto aos seus significados para o capital, pois na medida em que a luta não se volta contra a fábrica no seu sentido mais amplo, contra a própria sociedade de trabalho, o único resultado prático dessa luta será o fortalecimento cada vez maior do próprio sistema, já que criariam as bases de sua readaptação contínua, através de novas tecnologias, novas racionalizações. É nesse sentido, que os autores chamam a atenção para o caráter "positivo" dos conflitos entre capital e trabalho.

Quanto a Luiz Werneck Vianna, a preocupação do seu trabalho diz respeito aos condicionamentos mútuos que se estabelecem entre espaço fabril e a conformação do sistema político estatal de controle da sociedade?

Vianna afirma que a sujeição imposta pelo sistema de máquinas e pelo taylorismo não é um resultado inevitável, na medida em que a socialização do trabalho, além de dominação, é também condição de emancipação. As contradições inerentes ao sistema de fábrica criam condições para a politização do espaço fabril e construção da cidadania operária (VIANNA, 1983).

Essas ideias nos remetem ao último grupo de estudos, saindo do campo da historiografia e entrando no âmbito dos estudos dos cientistas políticos e sociólogos, assim como o caso de Werneck Vianna. Refiro-me a dois ensaios de Maria Célia Paoli $(1982,1989)$. Em ambos, as questões centrais são as seguintes: como foi que no período Vargas, momento da emergência subordinada dos setores populares, os operários enfrentaram o cotidiano fabril determinado por um padrão de desenvolvimento industrial baseado, antes de tudo, no uso predatório e no controle despótico da força de trabalho, e como foi que, a partir do enfrentamento dessa realidade, criaram-se as condições para a formação da própria ideia de classe operária como realização preliminar à interferência autônoma no plano da política, alargando os espaços de cidadania e reivindicando mudanças no plano institucional capazes de consolidar suas conquistas e viabilizar seu projeto de sociedade?

A diferença entre os dois estudos diz respeito à ênfase do primeiro nas condições de gestação de uma consciência de classe operária no processo de sua constituição, enquanto o segundo reflete sobre as dimensões e o caráter da participação operária num plano mais amplo, não apenas na fábrica, mas na esfera do sistema político.

9 “A fábrica resume e condensa a política, na medida em que o tipo de controle ali exercido sobre a força de trabalho traduz a natureza específica de como se realiza o nível do político numa formação econômico-social" (VIANNA, 1983, p. 29-52). 
Os três blocos de estudos resumem-se no seguinte: 1) a fábrica enquanto campo do exercício despótico da autoridade patronal e suas consequências em termos de condições de trabalho; 2) a fábrica como peça fundamental nos mecanismos e nos aparelhos de dominação social e política, e, finalmente, 3) a fábrica enquanto espaço legítimo de atuação política e construção de uma cidadania operária. O critério de escolha do elenco de obras, mais do que preso aos debates internos de cada domínio do saber, esteve atrelado a estas diferentes possibilidades de abordagem da fábrica.

Uma problemática pouco trabalhada nos estudos mencionados diz respeito aos modelos de organização fabril e às representações sociais construídas em torno da fábrica subjacentes ao processo de industrialização e formação da burguesia industrial e da classe operária no Brasil. Entendemos que seria necessário um questionamento a respeito dos tipos de fábrica que se organizaram no Brasil, pois sua origem e evolução não resultaram de um processo puramente tecnológico e econômico e nem de uma mera imitação dos modelos estrangeiros. A instituição fabril resultou da história dos conflitos sociais e políticos: expressão concreta das representações e práticas dos agentes sociais envolvidos nesses conflitos e das escolhas históricas contextualizadas pelos processos políticos e econômicos.

Resta uma problemática pouco trabalhada nos estudos mencionados, isto é, quais os modelos de organização fabril e quais as representações sociais em torno da fábrica subjacentes ao processo de industrialização e formação da burguesia industrial e da classe operária no Brasil. Nos anos noventa alguns esforços foram realizados nesse sentido (GODOY, 1994). O fato, entretanto, é que já nessa década é perceptível uma mudança de foco nos estudos acadêmicos sobre o universo fabril. A correlação já apontada por Gramsci em texto clássico (GRAMSCI, 1980, p. 375-414) parece se confirmar, ou seja, o investimento político empresarial sobre o cotidiano do chão da fábrica está de alguma forma articulado com as configurações políticas dos espaços públicos institucionais. O que de fato assistiu-se a partir dos anos noventa foi a um esforço empresarial no sentido de reassumir o controle da fábrica e despolitizá-la, tal como demonstram os processos de reorganização produtiva e os novos modelos organizacionais implantados, como o toyotismo (HIRATA, 1993), seguidos de perto pela montagem de programas e estratégias de obtenção do consenso e colaboração funcional no interior das empresas brasileiras. Isso tudo se deu na medida mesmo em que se consolidou o processo de abertura 
política, a vigência de uma nova Constituição, a reorganização partidária e a remodelação dos canais de manifestação e participação institucional. Nesse sentido, parece que toda a atenção dedicada em desvendar o espaço fabril tal como apresentamos acima, bem como a formulação de novas perspectivas analíticas e chaves interpretativas, não apenas no campo do conhecimento histórico, estava muito colada na emergência dos movimentos sociais e operários e do novo sindicalismo dos anos setenta e oitenta.

Num exercício do que poderíamos chamar de crítica historiográfica, Adalberto Marson (1992) apontou dimensões presentes em algumas iniciativas acadêmicas, voltadas para o estudo da história do movimento operário no Brasil, que poderiam fazer as vezes de epitáfio crítico de um grupo de trabalhos que marcaram toda a década de oitenta principalmente, onde a problemática do espaço fabril emergia como o verdadeiro lugar do movimento operário (MUNAKATA, 1980). A partir de argumentação consistente, Marson aponta como as novas propostas de abordagem do movimento operário, voltadas para o deslocamento de foco - ou seja, não mais na sua atuação na esfera da política institucional e sindical, mas no chão da fábrica, e não mais nos grandes movimentos e eventos, mas nos fatos miúdos e cotidianos -, estavam articuladas por um projeto historiográfico que se apresentava como novo, mas que inadvertidamente reproduzia os mesmos procedimentos legitimadores dos modelos interpretativos dos quais procura se distanciar e busca superar. Vinha no bojo de um projeto de história aliado à militância política explícita, fundado numa compreensão específica da fusão teoria e prática, história-acontecimento e história-conhecimento, e numa proposta de identidade total do historiador com seu objeto de estudo, onde a reformulação dos critérios de reconstituição do passado (da história em geral) deveria nascer dos projetos políticos gestados no interior do próprio movimento operário do presente. Marson busca explicitar as estratégias de construção de legitimidade embutidas no lançamento e no desenvolvimento de um novo projeto historiográfico em torno da temática movimentos sociais e movimento operário no Brasil, onde as velhas interpretações devem ceder lugar a uma nova interpretação. Tais estratégias terminariam por anular, de certa forma, o potencial inovador trazido pelo novo projeto, uma vez que repunham a necessidade de estabelecer uma nova memória, contraposta à antiga, mas sem sair do seu campo de debate. Isso fica explícito na tentativa, por parte dos novos historiadores, de estabelecer um vínculo causal entre as 
greves operárias do $\mathrm{ABC}$ paulista, no final dos anos setenta, como ruptura factual detonadora de nova postura cognitiva sobre o real. Por outro lado, recolocavam nas mesmas bases a dependência teórica dos historiadores em relação ao desenvolvimento dos conceitos originários das outras áreas das ciências humanas, a partir da incorporação de uma linha interpretativa vinda da junção Michel Foucault, Steven Marglin e Cornelius Castoriadis, estes, sim, formuladores de nova perspectiva teórica causadora única do projeto historiográfico em questão.

Concordando ou não com a avaliação crítica apresentada por Adalberto Marson, o fato é que suas observações originam-se no mesmo ambiente intelectual dos anos 80 e sua proposta de fazer avançar o movimento de crítica da memória, onde se destaca o pensamento de Carlos Alberto Vesentini (1997) e não deixava de ser tributário das ideias, entre outras, de Foucault, por exemplo, e de sua proposta de análise dos dispositivos discursivos. Porém, é inegável que tal postura abria o leque das interpretações e colocava no centro do debate sobre as possibilidades das reconstituições históricas a reflexão recorrente que o historiador deveria fazer sobre seus próprios procedimentos, métodos e técnicas empregados no fazer historiográfico. Em outros termos, a necessidade do historiador, terminado seu trabalho, deixar às amostras os seus andaimes.

Como foi dito, os anos noventa assistiram a um recrudescimento dos estudos do movimento operário na ótica da sua ação e atuação nos espaços fabris. De fato, houve um esgotamento desse tipo de abordagem, pelo menos no campo da historiografia. O que não significa seu abandono completo. Mas perdeu o prestígio da novidade que gozou na década anterior. O espaço da fábrica não deixou de ser tematizado, mas a ação empresarial parece ter ganhado relevo. A atuação empresarial propriamente dita começa a merecer mais atenção, suas estratégias, métodos, reorganizações espaciais e de processos. O próprio vocabulário dos historiadores parece refletir os novos enfoques, pois pouco se fala de "burguesia industrial" e mais de "empresários industriais". Esse novo momento pode ser percebido a partir da emergência das discussões sobre a influência ou vigência do fordismo no Brasil ${ }^{10}$. Mais recentemente, e acompanhando um processo crescente

2007.

10 Veja, por exemplo, Schincariol, 2007; Botelho, 1997; Gounet, 1999; Zanetti e Vargas, 
de despolitização do próprio discurso do historiador e de abandono de um engajamento explícito, mas também, embora sem nenhum nexo causal aqui, um avanço no processo de profissionalização e consolidação da profissão do historiador, o estudo sobre a fábrica tem sofrido uma guinada estética e demonstrado uma preocupação pelos aspectos da arquitetura fabril e da sua importância como patrimônio cultural e histórico e de como isso reflete dimensões culturais da realidade (VICHNEWSKI, 2004), indicando que os movimentos de mudança no próprio campo do conhecimento histórico no Brasil sempre estiveram muito colados nos movimentos da historiografia europeia, sobretudo, e nos ritmos em que essas influências têm desembarcado por aqui.

\section{Considerações finais}

O que procuramos apresentar aqui foi um breve balanço historiográfico, destacando alguns estudos e, sobretudo, as tendências que se apresentam na temática em questão. Nosso propósito é essencialmente instrumental, ou seja, mapear um certo campo de pesquisa, identificando o que já se fez e as novas possibilidades em curso. Creio que essa dimensão dos empreendimentos historiográficos, seu caráter de instrumento de pesquisa e de ferramenta do ofício do historiador não devem se perder sob o risco de empobrecimento da prática científica. Atualmente, esboça-se no Brasil um processo de especialização dos estudos de historiografia e o consequente surgimento de publicações específicas, seminários temáticos nos congressos da área de história e até mesmo uma associação dos pesquisadores dessa linha de pesquisa. Tudo indica um contexto de definição de um campo de estudos e as consequentes disputas acadêmicas no sentido de ocupação de espaços e busca de legitimidade. Entendemos que o crescente aperfeiçoamento e sofisticação dos procedimentos analíticos decorrentes devem retornar para a prática e formação geral do historiador. E agora de uma maneira diferente em relação ao modo como tradicionalmente os capítulos introdutórios de análise bibliográfica das dissertações e teses eram realizados. A prática usual de se iniciar os trabalhos acadêmicos com avaliações mais ou menos abrangentes daquilo que os pares produziram sobre 
o tema nem sempre correspondia a uma retomada sistemática do debate no desenvolvimento da pesquisa e na apresentação dos resultados. Nem sempre refletia, por outro lado, uma tomada de consciência do historiador a respeito da historicidade de sua própria pesquisa. Nesse sentido, a atual consolidação de linha de trabalho em torno dos estudos de historiografia pode ao mesmo tempo representar um reflexo da maturidade, qualitativa e quantitativa, dos estudos históricos no Brasil, mas também, e sobretudo, abrir possibilidades para seu avanço. O balanço dos estudos sobre o espaço fabril apresentado acima espera poder se inscrever nessa última tendência.

Por fim, mas não menos importante, a trajetória dos estudos sobre o sistema fabril entre os historiadores parece confirmar algumas das características mais evidentes da historiografia brasileira, a saber, seu apego e andamento muito próximos dos movimentos da historiografia europeia, principalmente. Ao que tudo indica, os ritmos e rumos da produção historiográfica brasileira apresentam-se como tributários dos ritmos e rumos da historiografia exógena e dependente dos seus fluxos e refluxos, inexistindo, portanto, um crescimento interno seguindo um esquema de sedimentação. Talvez a atual emergência das análises historiográficas explicite esse ponto e estimule reflexões no sentido de superar esse problema.

\section{Referências Bibliográficas}

BENDIX, Reinhard. Trabajo y autoridad en la industria. Trad. Ötalo Manzi y Ricardo Malf. Buenos Aires: EUDEBA, 1966.

BOTELHO, Adriano. Do fordismo à produção flexivel. A produção do espaço num contexto de mudanças das estratégias de acumulação de capital. Dissertação (Mestrado) - FFLCH-USP. São Paulo, 1997.

CASTORIADIS, Cornelius. L'institution imaginaire de la société. Paris: Seuil, 1975, p. 89-103. 1985. . A experiência do movimento operário. Trad. port. São Paulo: Brasiliense,

CANO, Wilson. Raizes da concentração industrial em São Paulo. São Paulo: T.A. Queiroz, 1986. 
DEAN, Warren. A industrialização de São Paulo: 1880-1945. São Paulo: Bertrand Brasil, 2001.

DECCA, Edgar de. O silêncio dos vencidos. 3. ed. São Paulo: Brasiliense, 1986. . A ciência da produção: fábrica despolitizada. In: . Op. cit., 1986. . O nascimento das fábricas. 5. ed. São Paulo: Brasiliense, 1987.

DICKSON, David. Tecnologia alternativa. Trad. esp. Madri: Blumes Ediciones, 1978.

DINIZ, Eli. Empresário, estado e capitalismo no Brasil: 1930-1945. Rio de Janeiro: Paz e Terra, 1978.

FAUSTO, Boris. Estado, classe trabalhadora e burguesia industrial (1920-1945): uma revisão. Novos Estudos Cebrap, São Paulo, v. 20, p. 6-37, 1988.

FERNANDES, Florestan. Notas de livros. Revista Brasileira de Estudos Políticos, v. II, n. 6, p. 223-225, julho de 1959.

FOUCAULT, Michel. Vigiar e punir. História da violência nas prisões. Trad. port. 6. ed. Petrópolis: Vozes, 1987.

FURTADO, Celso. Formação econômica do Brasil. São Paulo: Companhia das Letras, 2007.

GORZ, Andre (Org.). Crítica da divisão do trabalho. Trad. Estela S. Abreu. São Paulo: Martins Fontes, 1980.

1968.

. Estratégia operária e neocapitalismo. Trad. port. Rio de Janeiro: Zahar,

. Adeus ao proletariado. Para além do socialismo. Trad. port. Rio de Janeiro: Forense Universitária, 1982.

GOUNET, Thomas. Fordismo e toyotismo na civilização do automóvel. São Paulo: Boitempo Editorial, 1999.

GRAMSCI, Antonio. Americanismo e fordismo. In: Maquiavel, a política e o Estado Moderno. Rio de Janeiro: Civilização Brasileira, 1980, p. 375-414.

HABERMAS, J. Técnica e ciência enquanto Ideologia. In: BENJAMIN, W. et al. Textos escolhidos. São Paulo: Abril Cultural, 1980, p. 313-343.

HIRATA, Helena (Org.). Sobre o modelo japonês: automatização. Novas formas de organização e de relações de trabalho. São Paulo: Edusp, 1993.

HOBSBAWM, Eric. História operária e ideologia. In: . Mundos do trabalho: novos estudos sobre história operária. Trad. port. Rio de Janeiro: Paz e Terra, 1987, p. 17-34. 
HUMPHREY, J. A fábrica moderna no Brasil. Revista de Cultura Política, n. 5/6, p. 41-57, 1981.

. Controle capitalista e luta operária na indústria automobilística brasileira. Petrópolis: Vozes, 1982.

LINHART, R. Lenin, os camponeses, Taylor. Rio de Janeiro: Marco Zero, 1983.

LOPES, Juarez Brandão. Sociedade industrial no Brasil. São Paulo: Difusão Europeia do Livro, 1964.

MANTOUX, Paul. A revolução industrial no século XVIII. Trad. port. São Paulo: Ed. Unesp/Ed. Hucitec, 1990.

MARONI, Amnéris. A estratégia da recusa. São Paulo: Brasiliense, 1982.

MARCUSE, H. A ideologia da sociedade industrial. Trad. Giasone Rebu. Rio de Janeiro: Zahar Editores, 1973.

MARGLIN, Steven. Origem e função do parcelamento das tarefas (para que servem os patrões?). In: GORZ, André. Crítica da divisão do trabalho. Trad. Estela S. Abreu. São Paulo: Martins Fontes, 1980, p. 37-78.

MATOS, Maria Izilda Santos de. Trama e poder. Tese (Doutoramento) - Departamento de História da FFLCH-USP. São Paulo, 1991 (mimeo).

MACHADO FILHO, Oswaldo. Sistema de fábrica e dominação social. Dissertação (Mestrado) - IFCH-UNICAMP. Campinas, 1984 (mimeo).

MELLO, João Manuel Cardoso de. O capitalismo tardio. São Paulo: Unesp, 2009.

MUNAKATA, Kazumi. O lugar do movimento operário. In: ENCONTRIO REGIONAL DE HISTÓRIA DE SÃO PAULO, 4. Anais... ANPUH-UNESP, Araraquara, 1980 , p. 61-81.

PAOLI, Maria Célia. Trabalhadores urbanos na fala dos outros: tempo, espaço e classe na história operária brasileira. Comunicação, n. 7, Museu Nacional, UFRJ, 1982.

. Trabalhadores e cidadania. Experiência do mundo público na história do Brasil moderno. Revista Estudos Avançados, v. 3, n. 7, p. 40-66, 1989.

; SADER, Eder; TELLES, Vera da Silva. Pensando a classe operária: os trabalhadores sujeitos ao imaginário acadêmico. Revista Brasileira de História, São Paulo, v. 6, p. 129-149, 1983.

PINHEIRO, Paulo S. Trabalho industrial no Brasil: uma revisão. Estudos Cebrap, v. 14, p. 119-131, 1977.

PRADO JR., Caio. Nacionalismo e desenvolvimento. Revista Brasiliense, n. 24, p. 9-15, julho-agosto de 1959. 
. O desenvolvimento econômico e o problema da capitalização. Revista Brasiliense, n. 34, p. 46-56, março-abril de 1961.

. Formação do Brasil contemporâneo. 17. ed. São Paulo: Brasiliense, 1981.

RIBEIRO, Maria Alice Rosa. Condições de trabalho na indústria têxtil paulista (1870-1930). São Paulo: Ed. Hucitec/Ed. Unicamp, 1988.

RODRIGUES, Leôncio Martins; MUNHOZ, Fábio. Bibliografia sobre trabalhadores e sindicatos no Brasil. Estudos Cebrap, v. 7, p. 153-167, 1974.

SCHINCARIOL, Vitor Eduardo. O Brasil sob a crise do fordismo. São Paulo: LCTE, 2007.

SILVA, Sérgio. Expansão cafeeira e origens da indústria no Brasil. São Paulo: Alfa-Ômega, 1996.

TURAZZI, Maria Inez. A euforia do progresso e a imposição da ordem. Rio de Janeiro: COPPE; São Paulo: Marco Zero, 1989.

VARGAS, João Tristan. O trabalho na ordem liberal. O movimento operário e a construção do Estado na Primeira República. Campinas/SP: UNICAMP/CMU, 2004.

VESENTINI, Carlos Alberto. A teia do fato. Uma proposta de estudo sobre a memória histórica. São Paulo: Hucitec, 1997.

VIANNA, Luiz Werneck. Estudos sobre sindicalismo e movimento operário: resenha de algumas tendências. BIB: Boletim Informativo e Bibliográfico de Ciências Sociais, Rio de Janeiro, v. 3, p. 9-24, 1978.

. Atualizando uma bibliografia: "novo sindicalismo", cidadania e fábrica. BIB: Boletim Informativo e Bibliográfico de Ciências Sociais, Rio de Janeiro, v. 17, p. 53-68, 1984.

. Fábrica e sistema político. In: . A classe operária e a abertura. São Paulo: Cerifa, 1983, p. 29-52.

VICHNEWSKI, Henrique Telles. As indústrias Matarazzo no interior paulista: arquitetura fabril e patrimônio industrial (1920-1960). Dissertação (Mestrado) UNICAMP. Campinas, 2004.

ZANETTI, Augusto; VARGAS, João T. Taylorismo e fordismo na indústria paulista. O empresariado e os projetos de organização racional do trabalho (1920-1940). São Paulo: Humanitas, 2007.

Recebido em 23/09/2008. Aprovado em 01/02/2011. 